\title{
Experiência com o uso de uma ferramenta para avaliação de desfecho na perspectiva do paciente
}

\section{Lima GA; Lima ARS; Silva GG; Colombari F}

Introdução: O controle e a manutenção do custo na saúde são um desafio mundial. A principal causa é o aumento do consumo de serviços de saúde seja pelo aumento da expectativa de vida, uso de novas tecnologias caras ou pelo modelo de remuneração por procedimento que, por sua vez, não destaca o desfecho clínico. Há necessidade de elaboração e estruturação de métricas de avaliação de desfechos na perspectiva do paciente. Saúde baseada em valor tem como objetivo otimizar os recursos disponíveis para a população, recompensando melhores resultados em termos de custo, qualidade de atendimento e resultados mensuráveis. O ICHOM foi fundado em 2012 para promover cuidado de saúde baseado em valor definindo padrões globais de avaliação de resultados relevantes ao paciente e promover a implantação desta avaliação pelo mundo.

Objetivo: Uso de uma ferramenta internacional para medir desfechos clínicos em ortopedia de um hospital privado brasileiro.

Metodologia: O protocolo ICHOM referência para este trabalho foi o Standard Set para Dor Lombar. Além dos indicadores sugeridos pelo ICHOM foram também incluídos alguns para melhor caracterização e gestão do hospital. Os pacientes foram avaliados no momento da internação, 90 e 180 dias. As avaliações foram feitas no formato de entrevista e dados coletados do prontuário.
Resultados: O estudo foi iniciado em janeiro de 2018 e até outubro foram incluídos 316 pacientes com dor lombar. Dos pacientes incluídos, tivemos retorno via telefone das avaliações de 90 dias de $32 \%$ no primeiro trimeste e $88 \%$ no segundo; já em relação a avaliação de 180 dias, tivemos um retorno de $50 \%$ no primeiro trimestre e iniciamos o segundo

\section{Acompanhamento Jan - Out 2018}

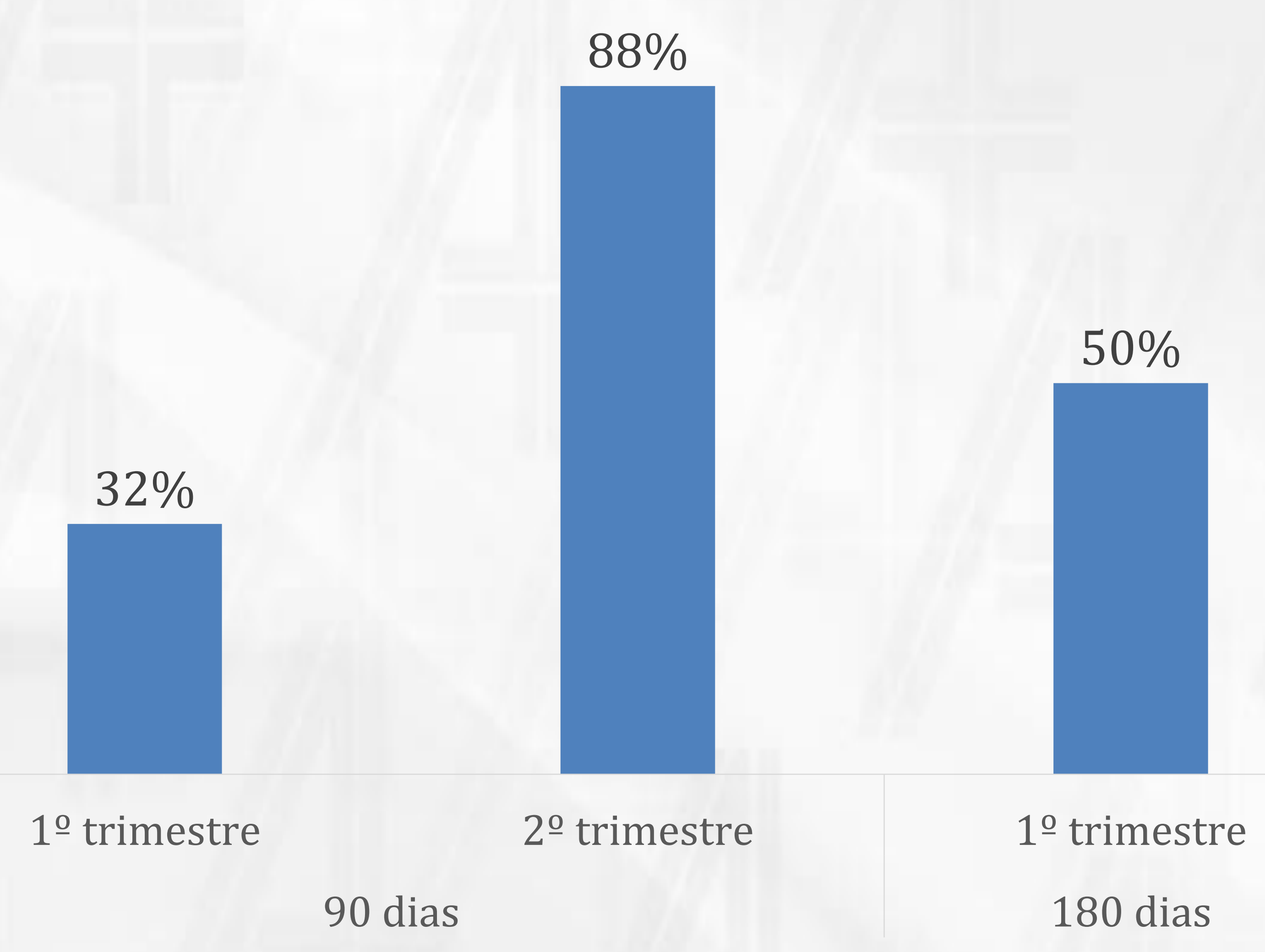

Conclusão: A implementação de um processo mais assertivo de busca ativa proporcionou elevação na taxa de sucesso de acompanhamento de longo prazo dos pacientes. Assim, o banco de dados tornou-se mais robusto para o desenvolvimento de um modelo de avaliação de equipes baseado em valor. A experiência foi avaliada como de sucesso pela equipe envolvida, há constantes ações para minimizar a perda de acompanhamento de pacientes e tem apresentado melhora de acordo com os resultados. 